\title{
PASAR NONGKRONG MODERN
}

\author{
Richard Juan Austen ${ }^{1)}$, Agustinus Sutanto ${ }^{2)}$
}

1) Program Studi S1 Arsitektur, Fakultas Teknik, Universitas Tarumanagara, rjausten2@gmail.com

2) Program Studi S1 Arsitektur, Fakultas Teknik, Universitas Tarumanagara, afirawiniera@gmail.com

\begin{abstract}
Abstrak
Daerah Khusus Ibukota Jakarta ( DKI Jakarta) adalah ibu kota negara dan kota terbesar di Indonesia. Jakarta sebagai ibu kota yang besar memiliki daya tarik sebagai tempat untuk mencari penghasilan, sangat memikat penduduk dari berbagai daerah di Indonesia untuk datang ke Jakarta yang menetap dan mengaku sebagai warga Jakarta. Jumlah warga pendatang di Jakarta sekitar 68.500 orang dan diprediksi sebanyak 60\% tinggal di Jakarta. Jakarta merupakan kota dengan tingkat pertumbuhan ekonomi yang cukup pesat. Saat ini, lebih dari 70\% uang negara beredar di Jakarta. Sejak awal tahun 1980, Pemerintah DKI Jakarta gencar membangun pusat-pusat perbelanjaan modern, atau biasa yang dikenal dengan mall dan plaza. Saat ini Jakarta merupakan salah satu kota di Asia yang banyak memiliki pusat perbelanjaan. Di samping pusat-pusat perbelanjaan mewah, Jakarta juga memiliki banyak pasar-pasar tradisional dan pusat perdagangan grosir. Untuk lingkungan yang lebih kecil, tersedia pula pusat belanja kebutuhan sehari-hari dengan harga yang terjangkau, seperti Indomaret dan Alfamart. Kota Jakarta sebagai ibukota dari Indonesia memfokuskan perkembangannya sebagai pusat perbisnisan Indonesia sehingga kini telah padat dipenuhi hunian dan bangunan tinggi. Kondisi kota Jakarta yang padat dengan penduduk dan bangunan, pasti banyak permasalahan yang muncul, dan yang menjadi permasalahan utama kota Jakarta seperti kemacetan lalu lintas, permasalahan sosial dan banjir. Kemacetan lalu lintas membuat warga Jakarta menjadi malas untuk keluar rumah sehingga gaya hidup yang individualistik membuat menurunnya interaksi sosial, juga menjadi penyebab stress. Kehidupan warga Jakarta yang tinggal di gedung-gedung bertingkat tinggi seperti Apartemen yang menjamur di Jakarta, yang sangat individual dan tidak bisa berinteraksi dengan lingkungan sekitar dan aktifitas sehari-hari hanya "terkurung" dalam unit apartemen membuat suasana yang membosankan dan bikin penghuninya menjadi stress. Permasalahan yang dihadapi oleh Kota Jakarta, tentunya membutuhkan pemecahan yang benar-benar harus dipikirkan oleh Pemerintah, khususnya Pemerintah Daerah Kota Istimewa Jakarta. Untuk itu Penulis mencoba membuat suatu fasilitas kota yang bisa sebagai jembatan penghubung antara kegiatan di rumah dan aktifitas kerja, dalam bidang sosial dan ekonomi berupa Third Place yang diberi nama Pasar Nongkrong Modern.
\end{abstract}

Kata kunci: modern; nongkrong; pasar

\section{Abstract}

The Special Capital Region of Jakarta (DKI Jakarta) is the country's capital and largest city in Indonesia. Jakarta as a large capital city has an attraction as a place to look for income, it is very attractive for residents from various regions in Indonesia to come to Jakarta who are settled and claim to be citizens of Jakarta. The number of migrants in Jakarta is around 68,500 people and it is predicted that as many as $60 \%$ live in Jakarta. Jakarta is a city with a fairly rapid economic growth rate. At present, more than $70 \%$ of state money is circulating in Jakarta. Since the early 1980s, the DKI Jakarta Government has been intensively building modern shopping centers, or commonly known as malls and plazas. At present Jakarta is one of the cities in Asia that has many shopping centers. In addition to luxury shopping centers, Jakarta also has many traditional markets and wholesale trade centers. For smaller environments, shopping centers for daily necessities are also available at affordable prices, such as Indomaret and Alfamart. The city of Jakarta as the capital of Indonesia focuses its development as the center of Indonesian business so that it is now densely filled with houses and tall buildings. The condition of the city of Jakarta is dense with residents and buildings, certainly there are many problems that arise, and the main problems of the city of Jakarta such as traffic jams, social problems and flooding. Traffic congestion makes Jakarta residents become lazy to leave the house so that an individualistic lifestyle makes social interaction decrease, also causes stress. The lives of Jakarta residents who live in high-rise buildings such as apartments that are mushrooming in Jakarta, which are very individual and cannot interact with the surrounding environment and daily activities are only "confined" in apartment units create a boring atmosphere and make residents become stressed. The problems faced by the City of Jakarta, of course, require solutions that really must be considered by the Government, especially the Local Government of the City of Jakarta. For that reason the author tries to make a city facility that can be a bridge between activities at home and work activities, in the social and economic fields in the form of Third Place, named Modern Hangout Market.

Keywords: hangout; market; modern 


\section{PENDAHULUAN}

Jakarta sebagai ibu kota yang besar memiliki daya tarik sebagai tempat untuk mencari penghasilan, sangat memikat penduduk dari berbagai daerah di Indonesia untuk datang ke Jakarta dan mengaku sebagai warga Jakarta. Jumlah warga pendatang di Jakarta sekitar 68.500 orang dan diprediksi sebanyak $60 \%$ tinggal di Jakarta. Kota Jakarta merupakan kota yang memiliki kompleksitas tinggi sehingga bisa disebut kota metropolis. Kota Jakarta sebagai ibukota dari Indonesia memfokuskan perkembangannya sebagai pusat perbisnisan Indonesia sehingga kini telah padat dipenuhi hunian dan bangunan tinggi.

Kondisi kota Jakarta yang padat dengan penduduk dan bangunan, pasti banyak permasalahan yang muncul. Sebagaimana umumnya kota megapolitan, kota yang berpenduduk di atas 10 juta, Jakarta memiliki masalah yaitu stress. Penyimpangan peruntukan lahan dan privatisasi lahan telah menghabiskan persediaan taman kota sehingga menambah tingkat stress warga Jakarta. Kehidupan warga Jakarta yang tinggal di gedung-gedung bertingkat tinggi seperti Apartemen yang menjamur di Jakarta, yang sangat individual dan tidak bisa berinteraksi dengan lingkungan sekitar dan aktifitas sehari-hari hanya "terkurung" dalam unit apartemen membuat suasana yang membosankan dan bikin penghuninya menjadi stress.

Kemacetan lalu lintas membuat warga Jakarta menjadi malas untuk keluar rumah sehingga gaya hidup yang individualistik membuat menurunnya interaksi sosial, juga menjadi penyebab stress. Sejak awal tahun 1980, Pemerintah DKI Jakarta gencar membangun pusat-pusat perbelanjaan modern, atau biasa yang dikenal dengan mall dan plaza. Saat ini Jakarta merupakan salah satu kota di Asia yang banyak memiliki pusat perbelanjaan. Beberapa pusat perbelanjaan modern di Jakarta memiliki luas yang cukup besar (lebih dari $100.000 \mathrm{~m} 2$ ). Di pusat-pusat perbelanjaan tersebut hadir berbagai waralaba internasional seperti Starbucks, Sogo, jaringan restoran siap saji McDonalds. Selain itu, perusahaan-perusahaan waralaba nasional juga memenuhi ruang pusat-pusat perbelanjaan tersebut, seperti Es Teler 77, J.Co dan Bakmie Gajah Mada.

Di samping pusat-pusat perbelanjaan mewah, Jakarta juga memiliki banyak pasar-pasar tradisional dan pusat perdagangan grosir antara lain ITC Cempaka Mas, ITC Mangga Dua, ITC Roxy Mas, Pasar Senen dan Pasar Tanah Abang. Selain itu, terdapat pula hypermarket yang menjadi tren belanja kalangan menengah di Jakarta, antara lain Carrefour, Hypermart, Giant, Lotte Mart, dan Ranch Market. Untuk lingkungan yang lebih kecil, tersedia pula pusat belanja kebutuhan sehari-hari dengan harga yang terjangkau, seperti Indomaret dan Alfamart. Di Jakarta terdapat pula pasar yang menjual barang-barang unik dan antik, seperti di Pasar Surabaya dan Pasar Rawabening.

Di Jakarta Barat terdapat beberapa pusat perbelanjaan, diantaranya :

- Central Park Mall, terletak di Jalan S. Parman, Jakarta Barat. Mall ini memiliki luas $167.000 \mathrm{~m} 2$. Desain mal ini meniru gaya unsur alam. Di mall ini terdapat sebuah food court, Sogo Department Store, Carrefour, dan CGV blitz. Mall ini terletak di kawasan Podomoro City yang dikembangkan oleh Agung Podomoro.

- Mall Taman Anggrek, terletak di Jalan S. Parman, Jakarta Barat. Dengan luas sekitar $130.000 \mathrm{~m} 2$, pusat perbelanjaan ini menyediakan lapangan ski indoor yang terbesar di Asia Tenggara.

- Mall Ciputra, berada di lokasi yang sangat strategis, yakni berada di depan jalan tol dan diapit oleh 2 universitas tekenal. Mall ini terletak di Jalan S. Parman, Jakarta Barat. Mall ini memiliki luas $80.000 \mathrm{~m} 2$. Diatas mall ini terdapat Hotel Ciputra Jakarta. Di mall ini terdapat Matahari Department Store dan Hero Supermarket.

Dalam rangka menciptakan Jakarta sebagai kota tujuan wisata belanja, setiap bulan JuniJuli pemerintah mengadakan program "Jakarta Great Sale". Program ini diadakan di pusatpusat perbelanjaan yang terdapat di Jakarta. Untuk mewujudkan Jakarta sebagai tujuan wisata 
belanja yang unggul, pemerintah saat ini sedang mengembangkan poros Casablanca-Satrio sebagai poros wisata belanja. Di poros ini, terdapat beberapa pusat perbelanjaan untuk berbagai segmen, yaitu Mal Ambassador, ITC Kuningan, Ciputra World Jakarta, Kuningan City, dan Kota Kasablanka. Tak jauh dari situ berdiri pula Plaza Festival, salah satu pusat kuliner yang menawarkan makanan-makanan khas Jakarta.

Jakarta merupakan kota internasional yang banyak menyajikan makanan khas dari seluruh dunia. Di wilayah-wilayah yang banyak didiami oleh para ekspatriat asing, seperti di daerah Menteng, Kemang, Pondok Indah, dan daerah pusat bisnis Jakarta, tidak sulit untuk menjumpai makanan-makanan khas asal Eropa, China, Jepang dan Korea. Makanan-makanan ini biasanya dijual dalam restoran-restoran mewah.

Di Jakarta, dan seperti kota-kota lainnya di Indonesia, Rumah Makan Padang merupakan restoran yang paling banyak dijumpai. Hampir di setiap sudut kota, dengan mudahnya dijumpai rumah makan yang manyajikan masakan asal Minangkabau ini. Jakarta juga memiliki makanan khasnya, yang paling terkenal adalah Kerak Telor, Soto Betawi, Kue Ape, Roti Buaya, Combro, dan Nasi Uduk. Sebagai tempat bermukimnya berbagai etnis di Indonesia, di sini juga bisa ditemukan berbagai macam makanan tradisional dari daerah lainnya, seperti Rawon, Rujak Cingur, dan Kupang Lontong. Di Jakarta juga terdapat Warung Tegal jumlahnya ada lebih dari 34.000 warung di Jabodetabek.

Wisata kuliner bisa ditemukan di berbagai tempat di Jakarta, terutama di mall-mall besar seperti "Jakarta Street Food Festival" yang diadakan setiap tahun di La Piazza Kelapa Gading yang menyajikan berbagai makanan jajanan kaki lima ( Food Street ) dan Kampoeng Legenda yang diadakan setiap tahun di Mall Ciputra yang menyajikan berbagai macam makanan khas daerah di Indonesia. Kota Jakarta merupakan kota yang memiliki kompleksitas tinggi sehingga bisa disebut kota metropolis. Kota Jakarta sebagai ibukota dari Indonesia memfokuskan perkembangannya sebagai pusat perbisnisan Indonesia sehingga kini telah padat dipenuhi hunian dan bangunan tinggi. Kondisi kota Jakarta yang padat dengan penduduk dan bangunan, pasti banyak permasalahan yang muncul, dan yang menjadi permasalahan utama kota Jakarta adalah :

- Kemacetan Lalu Lintas

Kemacetan adalah situasi atau keadaan tersendatnya atau bahkan terhentinya lalu lintas yang disebabkan oleh banyaknya jumlah kendaraan melebihi kapasitas jalan. Kemacetan banyak terjadi di kota-kota besar, terutamanya yang tidak mempunyai transportasi publik yang baik atau memadai ataupun juga tidak seimbangnya kebutuhan jalan dengan kepadatan penduduk, misalnya Jakarta. Kemacetan lalu lintas memberikan dampak negatif yang besar, antara lain :

Kerugian waktu, karena kecepatan perjalanan yang rendah ; Pemborosan energi karena pada kecepatan rendah konsumsi bahan bakar lebih tinggi ; Meningkatkan polusi udara karena pada kecepatan rendah konsumsi energi lebih tinggi; Meningkatkan stress pengguna jalan

- Sosial

Sebagaimana umumnya kota megapolitan, kota yang berpenduduk di atas 10 juta, Jakarta memiliki masalah yaitu stress.

- Penyimpangan peruntukan lahan dan privatisasi lahan telah menghabiskan persediaan taman kota sehingga menambah tingkat stress warga Jakarta.

- Kehidupan warga Jakarta yang tinggal di gedung-gedung bertingkat tinggi seperti Apartemen yang menjamur di Jakarta, yang sangat individual dan tidak bisa berinteraksi dengan lingkungan sekitar dan aktifitas sehari-hari hanya "terkurung" dalam unit apartemen membuat suasana yang membosankan dan bikin penghuninya menjadi stress.

- Kemacetan lalu lintas membuat warga Jakarta menjadi malas untuk keluar rumah sehingga gaya hidup yang individualistik membuat menurunnya interaksi sosial, juga menjadi penyebab stress. 
Permasalahan yang dihadapi oleh Kota Jakarta, tentunya membutuhkan pemecahan yang yang benar-benar harus dipikirkan oleh Pemerintah, khususnya Pemerintah Daerah Kota Istimewa Jakarta. Untuk itu Penulis mencoba membuat suatu fasilitas kota berupa tempat nongkrong ( third place ) sebagai penyeimbang kota.

Diharapkan proyek ini bisa menjadi jembatan penghubung antara kehidupan di rumah dan aktifitas kerja, dalam bidang sosial dan ekonomi. Menjadi wadah untuk kegiatan informal atau nongkrong menghabiskan waktu, menunggu redanya kemacetan lalu lintas sebelum pulang ke rumah dan menjadi wadah bagi warga kota Jakarta untuk berinteraksi dan bersosialisasi tanpa membedakan status sosial.

\section{KAJIAN LITERATUR}

Istilah "place" erat kaitannya dengan teori "space". Jika space berarti tiga dimensi yang membentuk place, sedangkan karakter diartikan sebagai suasana dari sebuah place. Ada hubungan antara landscape, pengalaman keseharian dengan faktor sosial dan ekonomi dalam pembentukan sebuah ruang. Istilah place dikaitkan dengan hubungan antara landscape, pengalaman keseharian dengan faktor sosial sebagai tempat-tempat yang unik, landscape, ruang-ruang komunal dibandingkan dengan pengalaman dan lingkungan tertentu ( Larice dan Macdonald, 2007 ). Pengertian "place" bukanlah sesuatu yang abstrak atau sekedar berupa konsep, tetapi "place" adalah sebuah fenomena kehidupan yang mengandung unsur pengalaman langsung, mempunyai arti dan merupakan sesuatu yang nyata yang di dalamnya terdapat aktivitas yang terjadi terus menerus. Keberadaan "place" sangatlah penting karena merupakan sumber dari sebuah identitas yang menunjukkan eksistensi individu maupun komunitas, bahkan lebih dari itu, "place" mempunyai hubungan yang emosional sangat dalam dan psikologi, baik itu seseorang maupun komunitas.

Menurut Ray Oldenburg ( The Problem of Place In America), istilah Third Place adalah istilah yang umum untuk menandakan tempat-tempat publik yang diadakan secara tetap, sukarela, informal untuk kegiatan informal, seperti berkumpul bersama keluarga atau teman (Larice dan Macdonald, 2007).

Ditinjau dari sejarahnya fenomena Tempat Ketiga (Third Place) muncul pada tahun 1980an di Amerika. Awalnya, keberadaan Tempat Ketiga tidak terlepas dari perkembangan revolusi industri yang terjadi di negara-negara Amerika yang memisahkan antara tempat tinggal dengan tempat kerja atau kawasan industri. Dimana tempat tinggal mengidentifikasikan rumah disebut sebagai First Place sedangkan tempat kerja disebut sebagai Second Place.

Dalam perkembangannya, pemisahan antara kawasan pemukiman dan kawasan kerja memunculkan kritik terhadap revolusi industri karena dianggap tidak manusiawi dan tidak menyediakan tempat atau kawasan rekreasi untuk para pekerja. Pembangunan pemukiman yang individual berpengaruh pada kehidupan sosial masyarakat. Dimana antar masyarakat tidak saling mengenal, meskipun dalam satu lingkungan. Lingkungan pemukiman yang terbentuk terasa sangat membosankan dan mengisolasi masyarakat. Aktivitas masyarakat khususnya remaja lebih banyak terjadi di dalam rumah dan tempat kerja yang secara menerus menimbulkan rasa bosan, namun ironisnya masyarakat tidak menemukan tempat di luar lingkungan rumah untuk berkegiatan dan berkumpul antar sesama remaja yang sebaya. Oleh karena itu dampak dari pemisahan pemukiman pada era revolusi industri adalah kebutuhan akan Tempat Ketiga ( third place ) guna menjembatani kehidupan dalam rumah dan aktifitas kerja dengan kegiatan informal.

Pada awalnya Tempat Ketiga (Third Place) berkonotasi buruk dan identik dengan budaya konsumtif. Istilah Third Place hanya mengarah kepada tempat-tempat hangout seperti kafe dan bar. Padahal istilah Third Place juga mengarah pada ruang-ruang terbuka kota, seperti taman kota, plaza, dan sidewalk dimana masyarakat dapat menghabiskan waktu untuk berkumpul dengan saudara atau teman-teman sambil menikmati suasana kota. Oleh Karena itu Third Place juga disebut sebagai a public meeting place (Larice dan Macdonald,2007).

The Great Good Place (Oldenburg, 1999) menuliskan bahwa The Third Place adalah tempat orang berkumpul selain di tempat bekerja atau di rumah. Inggris memiliki pub, Perancis memiliki cafe, dan Austria memiliki kedai kopi. Sekali waktu di Amerika Serikat, tempat ketiga umum termasuk toko negara, kantor pos, barber shop, salon rambut, toko soda, dan kedai 
minuman. Ray Oldenburg juga menjelaskan bahwa tempat ketiga memiliki ciri umum seperti :

a. Netral artinya semua orang bisa datang dan pergi tanpa harus terikat. Jika sesorang tidak ke tempat ketiga selama beberapa waktu maka saat orang tersebut kembali kesana tetap akan disambut dengan baik dan antusiasme.

b. Tidak terdapat perbedaan status dan tidak ada yang berkuasa atau yang mendominasi di tempat ketiga.

c. Kegiatan utama di tempat ketiga adalah komunikasi dengan teman-teman dan bukan untuk percakapan yang membosankan.

d. Dapat dicapai dengan mudah baik dari sisi waktu dan transportasi.

e. Tempat ketiga memiliki pengunjung tetap. Memang, pelanggan tetap menentukan tempat ketiga, tetapi orang baru juga bisa diterima tidak secara otomatis tetapi sering dengan dipermudah.

f. Sederhana dan bersahaja secara fisik.

g. Tempat yang menyenangkan.

h. Rumah yang jauh dari rumah, walaupun pengaturannya sangat berbeda dengan rumah, tempat ketiga sangat mirip dengan rumah yang baik dari segi kenyamanannya.

Setiap budaya mempengaruhi masyarakat dalam menggunakan ruang kota berbeda di setiap negara. Seperti budaya masyarakat Eropa dan Amerika, khususnya Perancis dan Jerman. Di Eropa kebiasaan beraktivitas atau melakukan pertemuan biasanya di tempattempat yang berskala besar. Seperti plaza, theater, mall. Sedangkan di Amerika skalanya lebih kecil, seperti cafe-cafe. Namun di periode industrialisasi, masyarakat ekonomi menengah di Amerika tidak terbiasa menghabiskan waktu di kafe-kafe. Mereka terbiasa menghabiskan waktu di dalam rumah. Ketidakbiasaan beraktifitas di luar rumah tersebut, serta tidak tersedianya tempat bersosialisasi dan rekreasi ternyata berdampak negatif pada bidang industri. Ketiadaan kehidupan informal membuat para pekerja mengalami stres sehingga berdampak pada produktivitas kerja. Dampaknya perusahaan harus menyediakan dana lebih untuk pengobatan bagi pekerja yang mengalami gangguan kesehatan dan mental. Disamping itu, berdampak juga pada biaya hidup yang mahal karena masyarakat harus membayar lebih untuk memperoleh tempat untuk kegiatan informalnya, sehingga masyarakat menjadi lebih konsumtif.

Di dalam masyarakat modern saat ini, kebutuhan akan Tempat Ketiga ( third place ) adalah sama pentingnya dengan kebutuhan tempat tinggal ( first place) dan juga tempat kerja (second place ). Berbeda dengan Amerika, di United Kingdom ( UK ), fenomena Tempat Ketiga ( third place) ini terjadi pada tahun 1999an. Dimana fenomena ini merupakan transformasi dari pemakaian ruang dalam ke ruang luar. Antara ruang privat dengan ruang publik. Sejak tahun 1999an, pada awalnya budaya ruang luar ini telah mengalami transformasi dari sekedar budaya makan dan minum yang dilakukan di ruang dalam (indoor) menuju ke budaya luar ruang ( outdoor ). Transformasi budaya ini memberikan pengalaman berbeda kepada masyarakat kota akan pengalaman ruang luar. Budaya penggunaan ruang luar ini di UK disebut sebagai Cafe Culture. Perilaku masyarakat dalam menggunakaan ruang luar ( urban outdoor) dianggap sebagai solusi untuk menyelesaikan persoalan ruang kota. Dengan demikian ruangruang kota yang awalnya sepi menjadi ramai kembali dan menarik untuk dikunjungi. Sedangkan di Jepang, keberadaan ruang kota seperti jalan tidak hanya sebagai jalur kendaraan namun juga memiliki peranan sangat penting untuk membentuk sebuah Tempat. Sebagaimana Shelton ( 1999 ) menuliskan :

"The street as stage. How different Japan..you, the walker, are not the actor."

Peran jalan dianggap penting, karena jalan itu sendiri merupakan aktor yang membentuk aktifitas masyarakat di ruang luar yang atraktif bukan hanya sekedar jalur tapi sebagai ruang informal, sosial dan komunal. Begitu juga dengan Sidewalk juga digunakan lebih dari sekedar jalur pejalan kaki namun untuk dapat berfungsi sebagai ruang sosial bahkan ekonomi. 


\section{METODE}

Manusia sebagai makhluk sosial tidak pernah lepas dari lingkungan yang membentuk diri mereka. Diantara sosial dan arsitektur dimana bangunan yang didesain manusia, secara sadar atau tidak sadar, mempengaruhi pola perilaku manusia yang hidup didalam arsitektur dan lingkungannya tersebut.

Behavioral Architecture merupakan salah satu metode dalam merancang yang mengutamakan perilaku pengguna sebagai faktor utama dalam mempertimbangkan alternatifalternatif rancangan. Menurut metode ini, beberapa ahli berpendapat bahwa setiap individu memiliki kegiatan dengan tujuannya masing-masing. Lalu tujuan tersebut dijadikan oleh manusia sebagai motivasi untuk melakukan suatu kegiatan tertentu untuk memenuhi keinginan dan kebutuhannya. Pada metode ini hal itu lah yang dijadikan sebagai analisis utama dalam perancangan. Analisis yang digunakan adalah hanya kepada perilaku yang terlihat dari beberapa individu baik itu yang dapat dilihat, diukur, dan digambarkan. Menurut Antonius, terdapat 2 skema yang mengambarkan behavioral architecture yaitu :

1. Arsitektur mempengaruhi Perilaku

Skema ini menjelaskan mengenai "Arsitektur membentuk Perilaku Manusia", dimana hanya terjadi hubungan satu arah yaitu desain arsitektur yang dibangun mempengaruhi perilaku manusia sehingga membentuk perilaku manusia dari desain arsitektur tersebut.

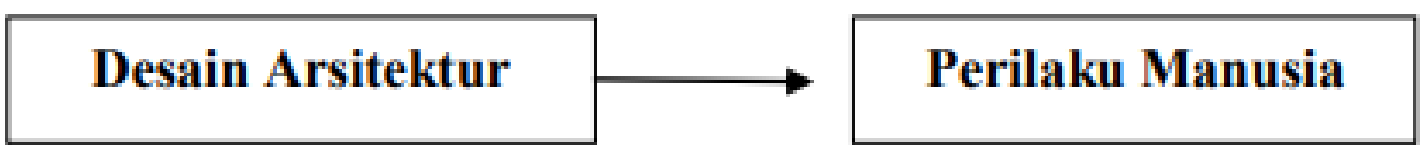

Sumber : Penulis, 2019

2. Perilaku mempengaruhi Arsitektur

Skema ini dijelaskan mengenai "Perilaku Manusia membentuk Arsitektur" dimana desain arsitektur yang telah terbentuk mempengaruhi perilaku manusia sebagai pengguna yang kemudian manusia mengkaji kembali desain arsitektur tersebut sehingga perilaku manusia membentuk kembali desain arsitektur yang baru.

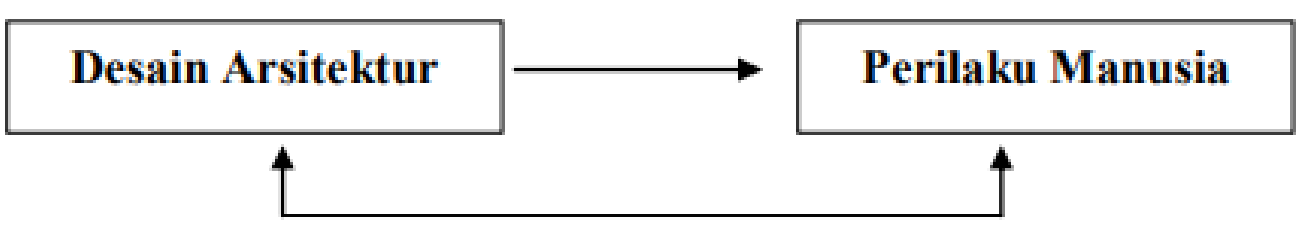

Sumber : Penulis , 2019

Selain mengutamakan perilaku pengguna dalam metoda merancang, terdapat berbagai proses dalam merancang. Berdasarkan buku berjudul Poetic of Architecture karya Antoniades, 1992. ada proses perancangan seperti transformasi, geometry, mimesis, metaphor, historicism and study of presedence, focus on material dan lain-lain. Namun dalam program ini, metoda perancangan yang akan digunakan adalah Transformasi.

Metoda perancangan Transformasi berkembang dengan mengkaitkan arsitektur kepada apapun sebagai pemicu ide yang diterjemahkan kedalam perupaan bentuk. Perupaan bentuk ini dapat terinspirasi dari objek nyata seperti lukisan, patung, lingkungan biologi dll, dapat pula dari objek yang tidak nyata tetapi dapat ditarik suatu benang merah. Contoh arsitektur yang mengambil metoda ini adalah Wyoming American Heritage dan Hongkong aptist University. 


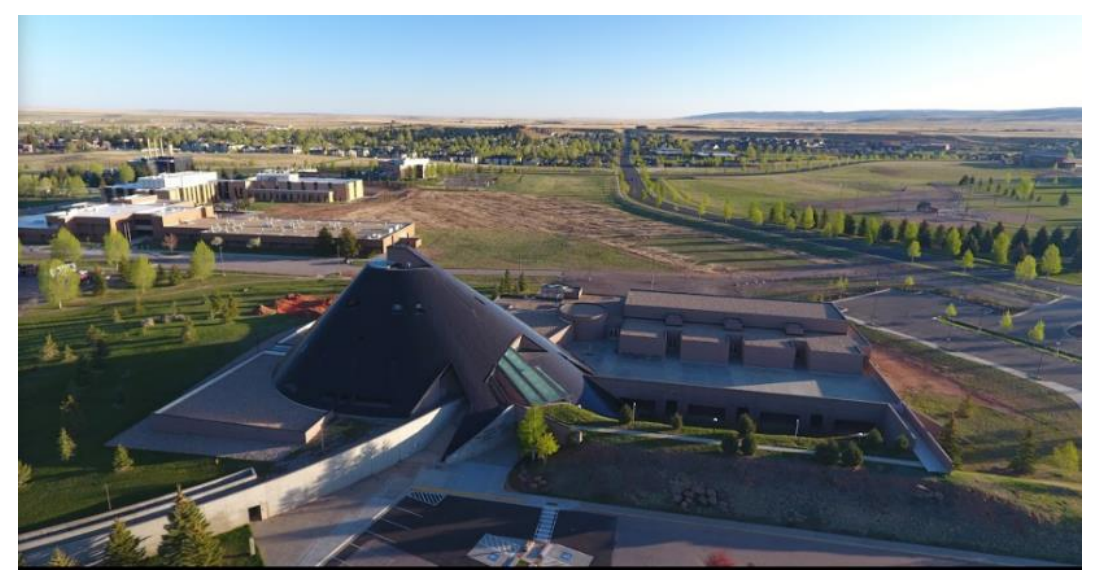

Gambar 1. Wyoming American Heritage Center Sumber : Wikipedia, 2019

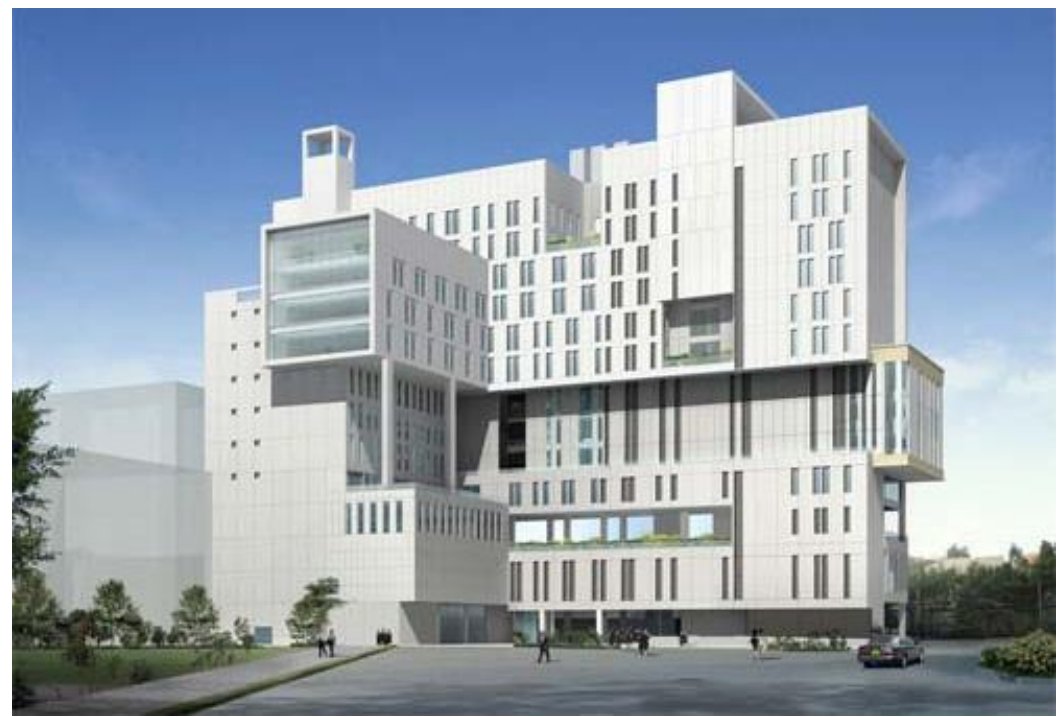

Gambar 2. Gambar Hongkong Baptist University Sumber : Wikipedia, 2019

Transformasi dapat diartikan perubahan dari benda asal menjadi benda yang baru. Baik perubahan yang sudah tidak memiliki atau memperlihatkan kesamaan atau keserupaan dengan benda asalnya, maupun perubahan yang benda baru masih menunjukan petunjuk benda asalnya. baik itu dengan cara digeser, dipotong, dikurangi dan di tambah di bagian tertentu. Transformasi ada di setiap bagian perancangan, karena kita mengolah sebuah bentuk selalu menggunakan yang namanya transformasi.

Kategori Transformasi (Laseau, 1980 dalam Sembiring, 2006):

1. Transformasi bersifat Topologikal (geometri), bentuk geometri yang berubah dengan komponen pembentuk dan fungsi ruang yang sama

2. Transformasi bersifat Gramatika hiasan (ornamental), dilakukan dengan menggeser, memutar, mencerminkan, menjungkirbalikkan, melipat, dll

3. Transformasi bersifat Reversal (kebalikan), pembalikan citra pada figur objek yang akan ditransformasi dimana citra objek dirubah menjadi citra sebaliknya

4. Transformasi bersifat Distortion (merancukan), kebebasan perancang dalam beraktivitas.

Perancangan untuk program ini menggunakan stategi survey tapak, survey literature dan pengamatan ( observasi).

Survey tapak : meneliti lokasi tapak dan potensi-potensi tapak serta lingkungannya yang menguntungkan untuk program ini. Lalu Survey literature : mengadakan study terhadap bukubuku tentang bangunan-bangunan third place dan bangunan yang menggunakan metoda 
perancangan metafora, yang mendukung program ini. Selanjutnya, Pengamatan ( observasi ) : mengamati perilaku orang yang sedang nongkrong di kaki lima sampai dengan di mall untuk menjadi faktor utama dalam metoda perancangan.

Perancangan Pasar Nongkrong Modern ini mengutamakan perilaku orang-orang yang nongkrong agar mereka merasa nyaman sehingga desain yang diterapkan dipengaruhi perilaku pengunjungnya dan desain aristekturnya mengambil metoda transformasi sehingga mempunyai tampilan yang unik, yang dapat menjadi icon ( ciri khas ) dari Pasar Nongkrong Modern ini.

Metoda transformasi dalam proyek ini dipicu dari ide rasi bintang Gemini yang mempunyai sifat interaksi dan komunikasi yang diterjemahkan dalam perupaan bentuk lambang rasi bintang Gemini menjadi bentuk baru dengan memotong bentuk aslinya untuk sirkulasi antar bangunan yang mengikat bangunan yang satu dengan yang lain sebagai bentuk interaksi antar bangunan. Pengolahan façade bangunan bersifat transformasi gramatikal hiasan (ornamental).

\section{DISKUSI DAN HASIL}

\section{Pengenalan Kawasan}

Analisis pertimbangan kawasan diawali dengan peninjauan Jakarta. Sebagai kota metropolitan, Jakarta telah tumbuh begitu pesat dengan padatnya penduduk dan bangunan tinggi sehingga dibutuhkan suatu tempat yang bisa menjadi tempat bagi masyarakat untuk bersosialisasi dan berinteraksi. Selanjutnya, dilakukan analisis aspek strategis, hal ini dilakukan untuk menganalisis kawasan dari beberapa aspek terkait yang relevan. Survey pada daerah kawasan Jalan Panjang Raya, Kedoya Utara yang minim tempat nongkrong sebagai Third Place. Di kawasan ini terdapat komplek perumahan dan komplek ruko dan beberapa bangunan bertingkat tinggi sebagai gedung perkantoran. Pencapaian ke kawasan ini bisa dicapai dengan menggunakan transportasi umum seperti angkutan umum ( angkot ), kopaja dan banyak ojek motor.

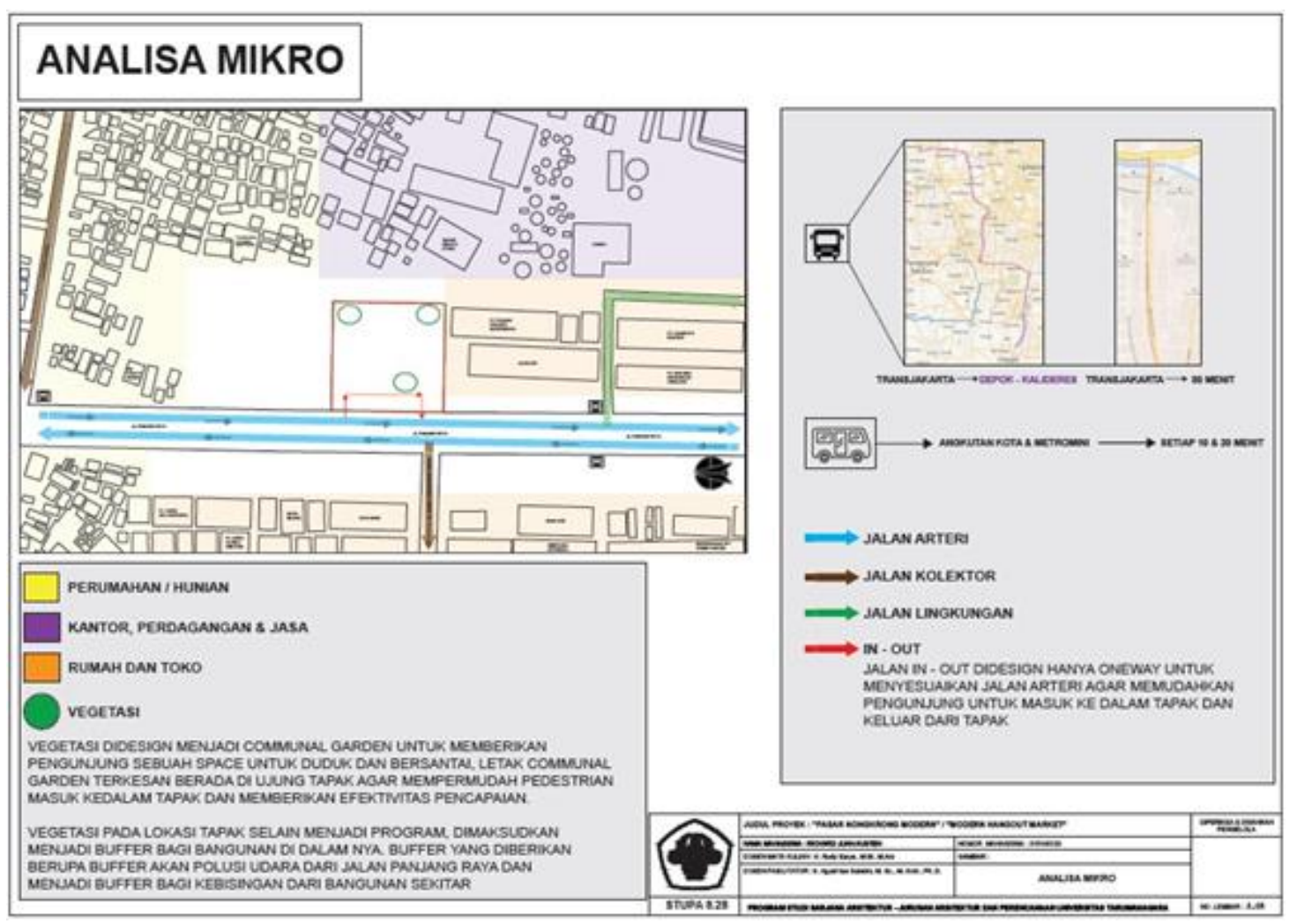

Gambar 3. Titik transportasi yang berhubungan

Sumber : Penulis, 2019 


\section{Konsep Perancangan}

Program Ruang

Tabel 1. Program Ruang

\begin{tabular}{|c|c|c|c|}
\hline No. & Penunjang & Nama Ruangan & Luasan \\
\hline 1 & \multirow{6}{*}{ Utama } & Food Market & $351.6 \mathrm{~m}^{2}$ \\
\hline 2 & & Cafe & $287 \mathrm{~m}^{2}$ \\
\hline 3 & & Food Court & $679.6 \mathrm{~m}^{2}$ \\
\hline 4 & & Food Store & $435.36 \mathrm{~m}^{2}$ \\
\hline 5 & & Floating Market & $622.66 \mathrm{~m}^{2}$ \\
\hline 6 & & Communal Garden & $963.67 \mathrm{~m}^{2}$ \\
\hline 7 & \multirow{4}{*}{ Pendukung } & Street Musician Performance & $200.7 \mathrm{~m}^{2}$ \\
\hline 8 & & Lounge & $214.6 \mathrm{~m}^{2}$ \\
\hline 9 & & Mini Café & $66 \mathrm{~m}^{2}$ \\
\hline 10 & & Café Semi Outdoor & $108.3 \mathrm{~m}^{2}$ \\
\hline 11 & \multirow{3}{*}{ Servis } & Area Parkir & $344.71 \mathrm{~m}^{2}$ \\
\hline 12 & & Basement (Utilitas) & $575.75 \mathrm{~m}^{2}$ \\
\hline 13 & & Ruang Pengelola & $155 \mathrm{~m}^{2}$ \\
\hline
\end{tabular}

Sumber : Penulis, 2019

Tapak

Tapak berada di Jalan Panjang Raya, Kedoya Utara, Kebun Jeruk, Jakarta Barat, DKI Jakarta dengan luas tanah $5.600 \mathrm{~m} 2$ yang memiliki zona perkantoran, dagang dan jasa. Maksimal ketinggian bangunan 4 ( empat) lantai. Dinding luar bangunan mengikuti garis sempadan bangunan yang telah ditetapkan. Pada tapak dibuat banyak area terbuka hijau di antara bangunan yang berfungsi sebagai sirkulasi udara dan pencahayaan alami.

Tabel 2. Besaran Luas Proyek dan Data Tapak

\begin{tabular}{lcc}
\hline & Desain Program & Ketentuan \\
\hline KDB (Koefision Dasar Bangunan) & $4105 \mathrm{~m}^{2}$ & $4380 \mathrm{~m}^{2}$ \\
\hline KTB (Koefision Tapak Basement) & $574.28 \mathrm{~m}^{2}$ & $55 \%$ \\
\hline KLB (Koefision Luas Bangunan) & 7183.5 & $15615 \mathrm{~m}^{2}$ \\
\hline KDH (Koefision Dasar Hijau) & $1235.73 \mathrm{~m}^{2}$ & $30 \%$ \\
\hline
\end{tabular}

Sumber : Penulis, 2019

\section{Gubahan Massa}

Tabel 3. Proses pembentukan Gubahan Massa

\begin{tabular}{l} 
Strategi Design \\
\hline $\begin{array}{l}\text { Gubahan massa awal mengikuti bentuk tapak } \\
\text { dan mengambil unsur dari rasi bintang Gemini }\end{array}$ \\
$\begin{array}{l}\text { Perubahan bentuk gubahan massa terjadi } \\
\text { karena sirkulasi antar bangunan sebagai } \\
\text { wujud interaksi }\end{array}$ \\
$\begin{array}{l}\text { Bentuk Facade gubahan massa mengikuti alur } \\
\text { bentuk tapak dan sekitarnya }\end{array}$ \\
$\begin{array}{l}\text { Penggunaan Vegetasi sebagai buffer dan } \\
\text { Program pada bangunan }\end{array}$
\end{tabular}

Sumber : Penulis, 2019 


\section{Sirkulasi pada Tapak dan Bangunan}

Sirkulasi mengikuti pola pergerakan manusia dari suatu tempat ke tempat lain dan membentuk sebuah keterhubungan antar bangunan. Sirkulasi dalam bangunan yang menerus agar pengunjung dapat menjelajahi seluruh ruangan dan kegiatan yang disajikan. Namun, disediakan juga akses langsung untuk pengguna khusus dengan sistem vertikal tangga.

\section{Façade Bangunan}
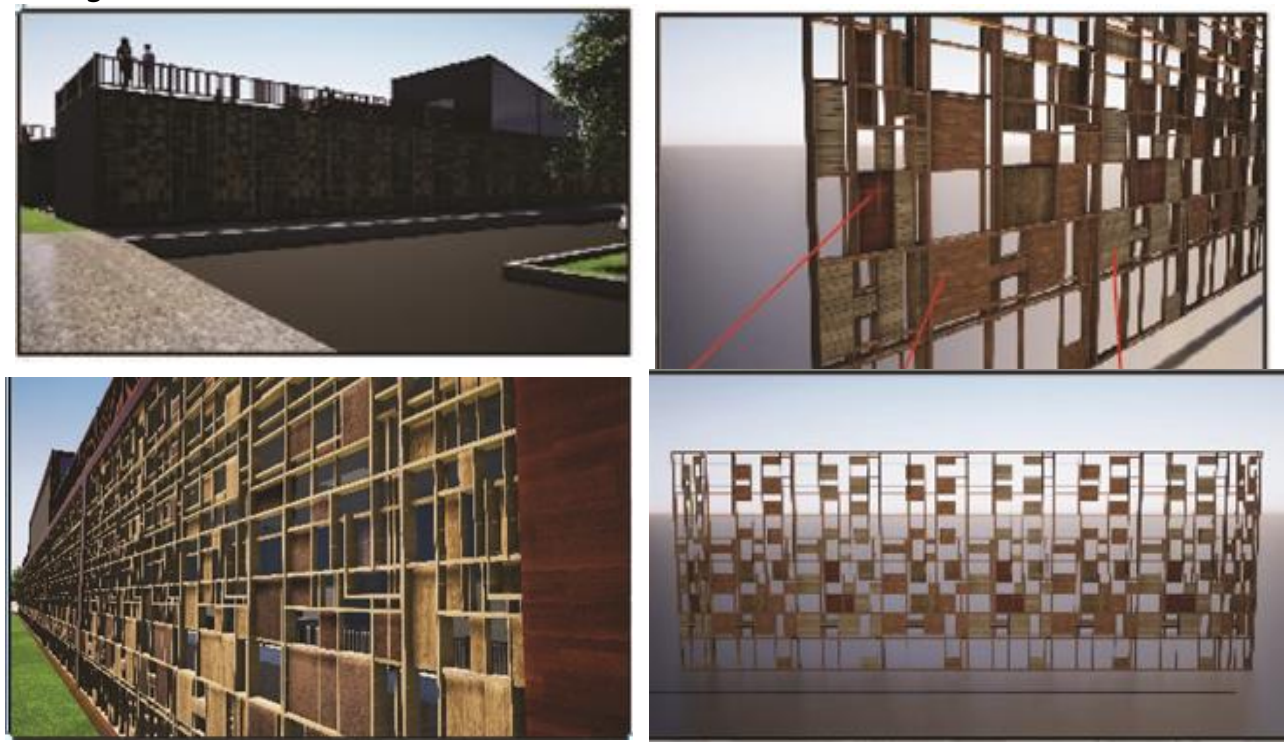

Gambar 4. Gambar Konsep Desain Façade

Sumber : Penulis, 2019

Pada fasade tertentu di setiap bangunan yang berada di sisi perimeter tapak menggunakan second skin yang berfungsi sebagai penahan cahaya dari luar sehingga panas matahari tidak langsung masuk ke dalamm bangunan dan second skin ini juga berfungsi sebagai estetika bangunan. Second skin ini merupakan transformasi gramatikal hiasan (ornamental) yang menggunak bahan kayu untuk mencerminkan kesederhanaan.

\section{Denah dan Pembagian Ruang}

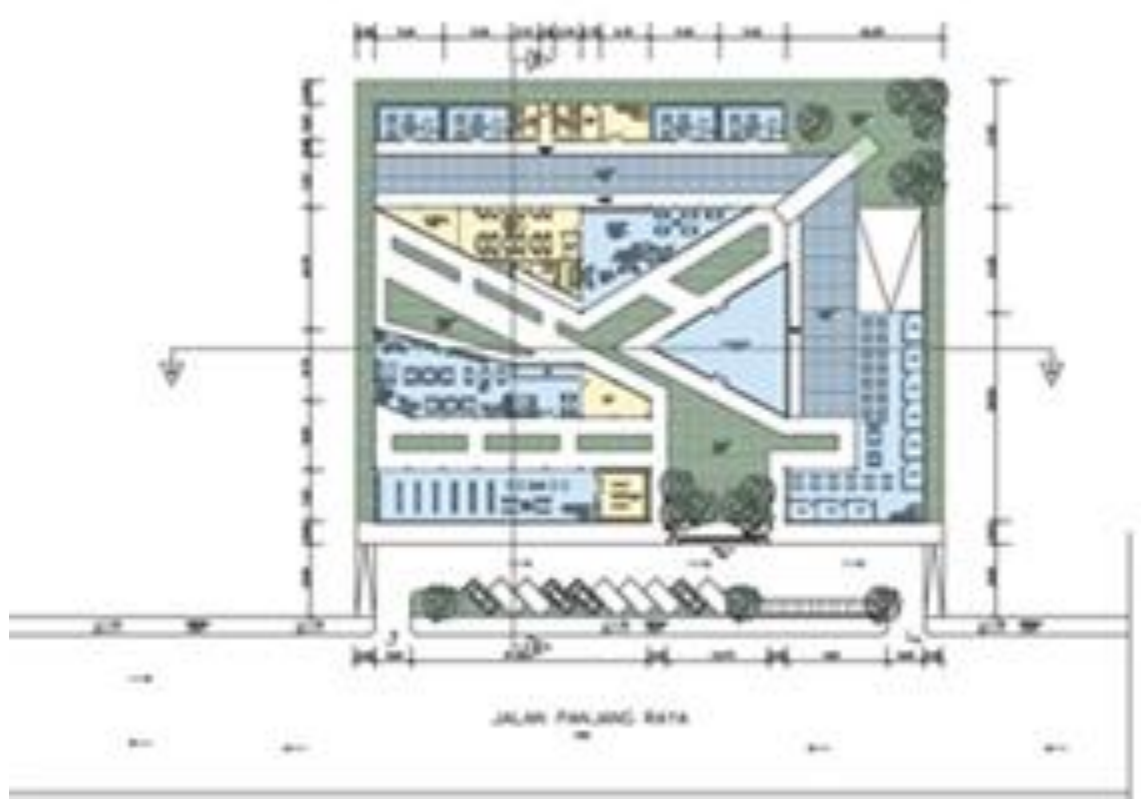

Gambar 5. Gambar Site Plan

Sumber : Penulis, 2019 
Perancangan pada proyek ini dilakukan dengan melakukan pembagian zonasi per lantai berdasarkan alur kegiatan dan hubungan antar ruang. Pada lantai dasar terdapat area drop off yang langsung tersambung dengan communal garden, area komersil, kantor pengelola dan floating market. Entrance utama pejalan kaki memiliki akses paling dekat dengan communal garden dan terdapat selasar untuk memudahkan perpindahan pengunjung dari bangunan satu ke bangunan lain. Seluruh entrance memiliki akses langsung terhadap inner courtyard yang berfungsi sebagai area duduk ( communal garden ) dan penghijauan.

Sirkulasi pada bangunan menerus dengan menggunakan selasar yang mengikat bangunan yang satu dengan bangunan yang lain agar pengunjung bisa menjelajahi seluruh bangunan dan mengikuti seluruh kegiatan yang ada. Menuju ke lantai dua juga terdapat selasar yang mengikat bangunan yang satu dengan yang lainnya berupa pedestrian ways. Namun terdapat juga akses langsung untuk para pengunjung berupa tangga. Selain area komersil, terdapat juga area service yang berada di lantai basement agar tidak mengganggu kegiatan komersil di lantai atasnya. Area roof top juga terdapat beberapa communal garden yang bisa diakses melalui tangga.
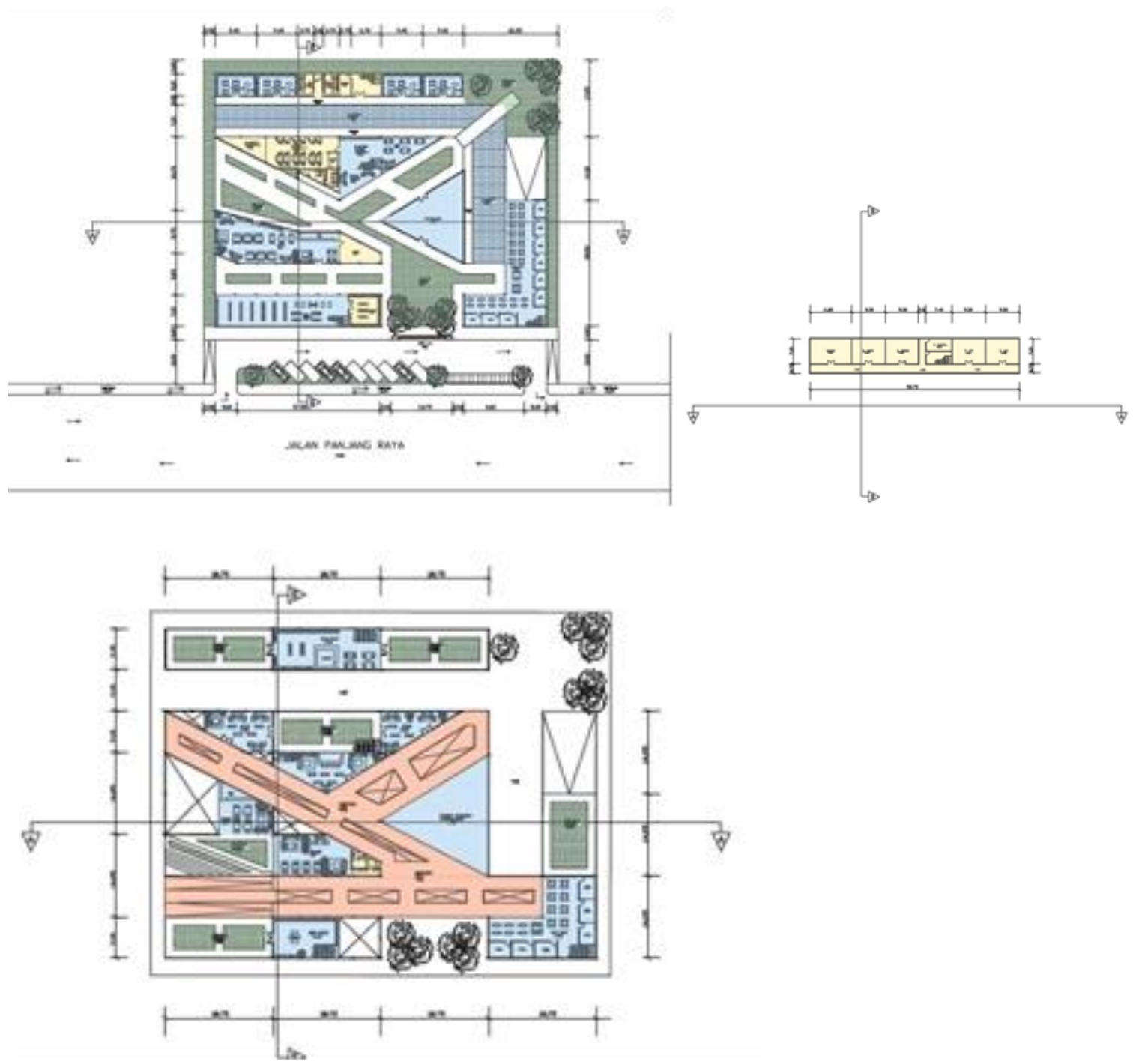

Gambar 6. Gambar Denah Sumber : Penulis, 2019 


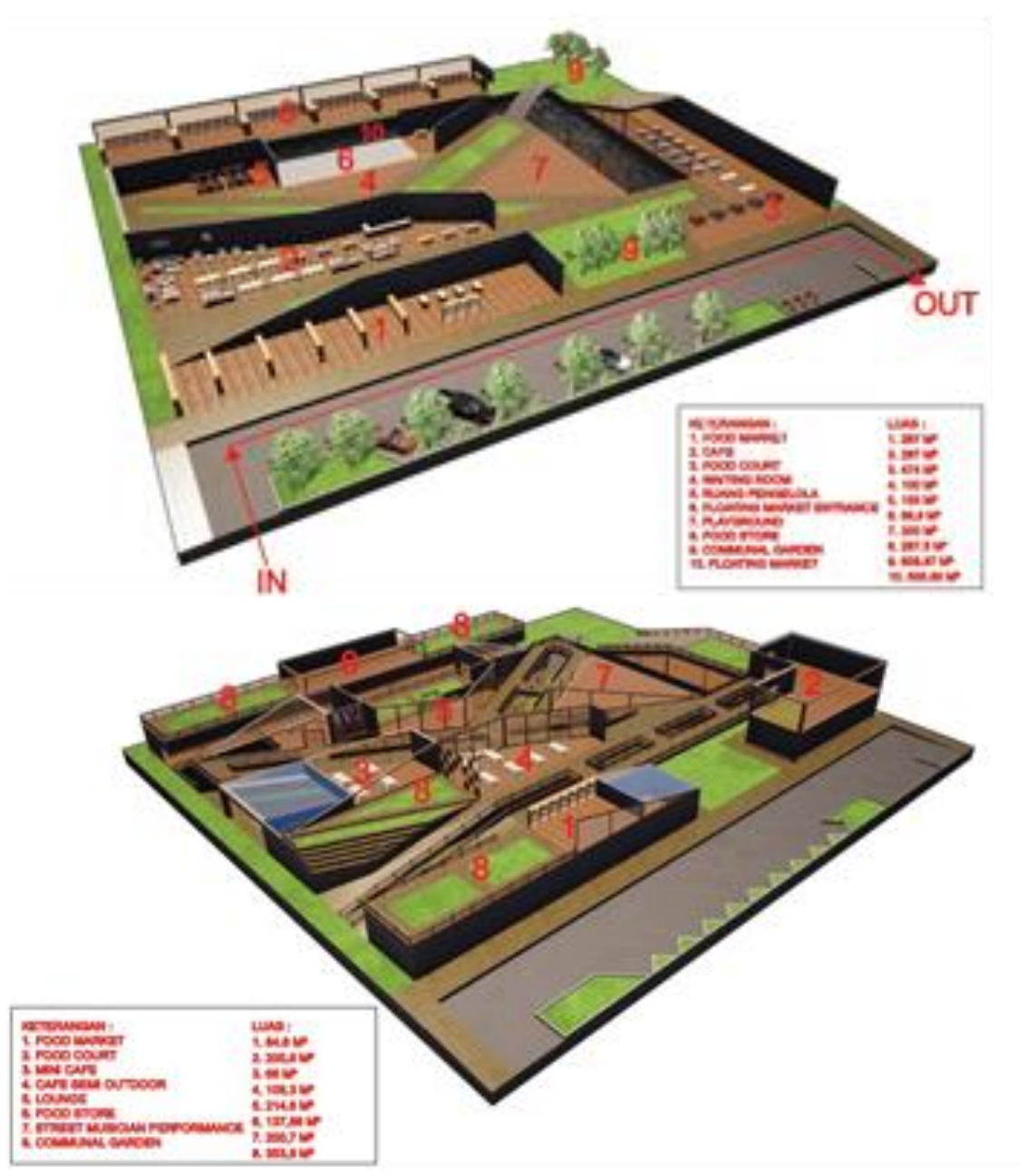

Gambar 7. Gambar Exploded

Sumber : Penulis, 2019

Struktur

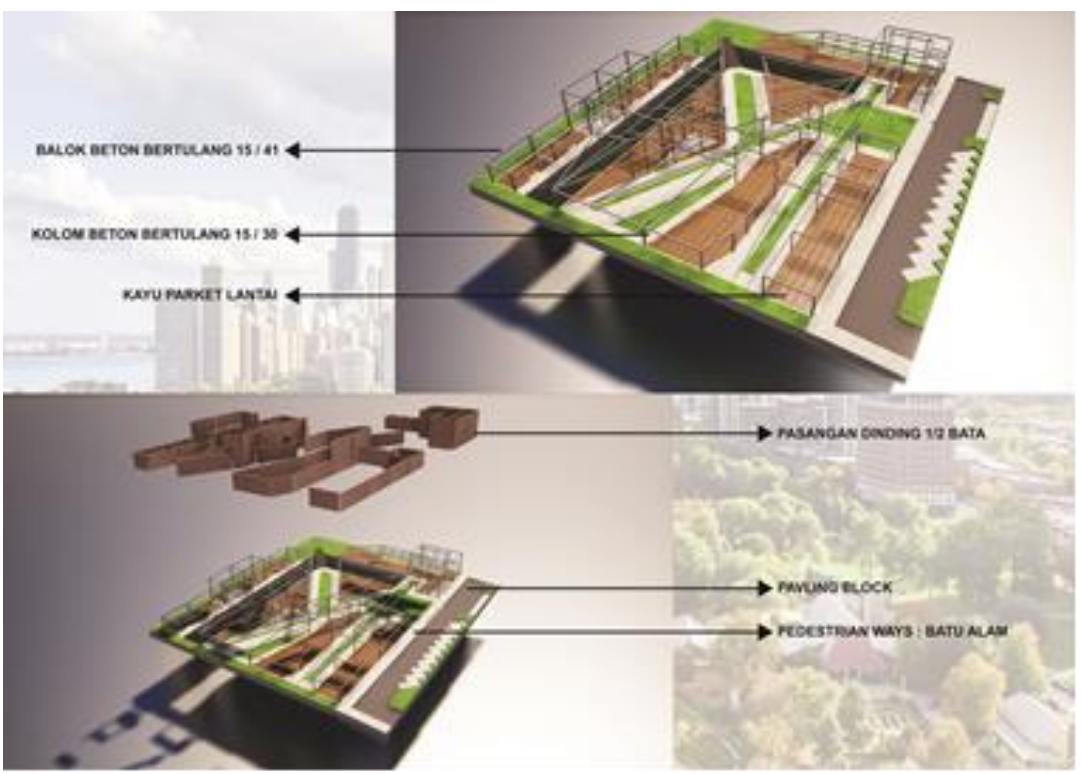

Gambar 8. Gambar Axonometri Struktur

Sumber : Penulis, 2019 
Struktur bangunan menyesuaikan dengan besar dan tinggi bangunan. Modul kolom yang digunakan mengikuti bentuk tapak (linear) karena bentuk dasar bangunan yang berupa kotak. Jarak antar kolom adalah kelipatan 4 meter mengikuti lebar bangunanya masing-masing yang terbuat dari bahan beton bertulang. Balok induk dengan ukuran $40 \mathrm{~cm} \times 15 \mathrm{~cm}$ terbuat dari bahan beton bertulang. Balok anak berukuran $20 \mathrm{~cm} \times 15 \mathrm{~cm}$. Ketebalan sheer wall $15 \mathrm{~cm}$ yang digunakan pada basement dan terbuat dari bahan beton bertulang. Jembatan penghubung antar bangunan terbuat dari bahan beton bertulang dengan ketebalan plat beton $15 \mathrm{~cm}$.

\section{Mekanikal dan Elektrikal}
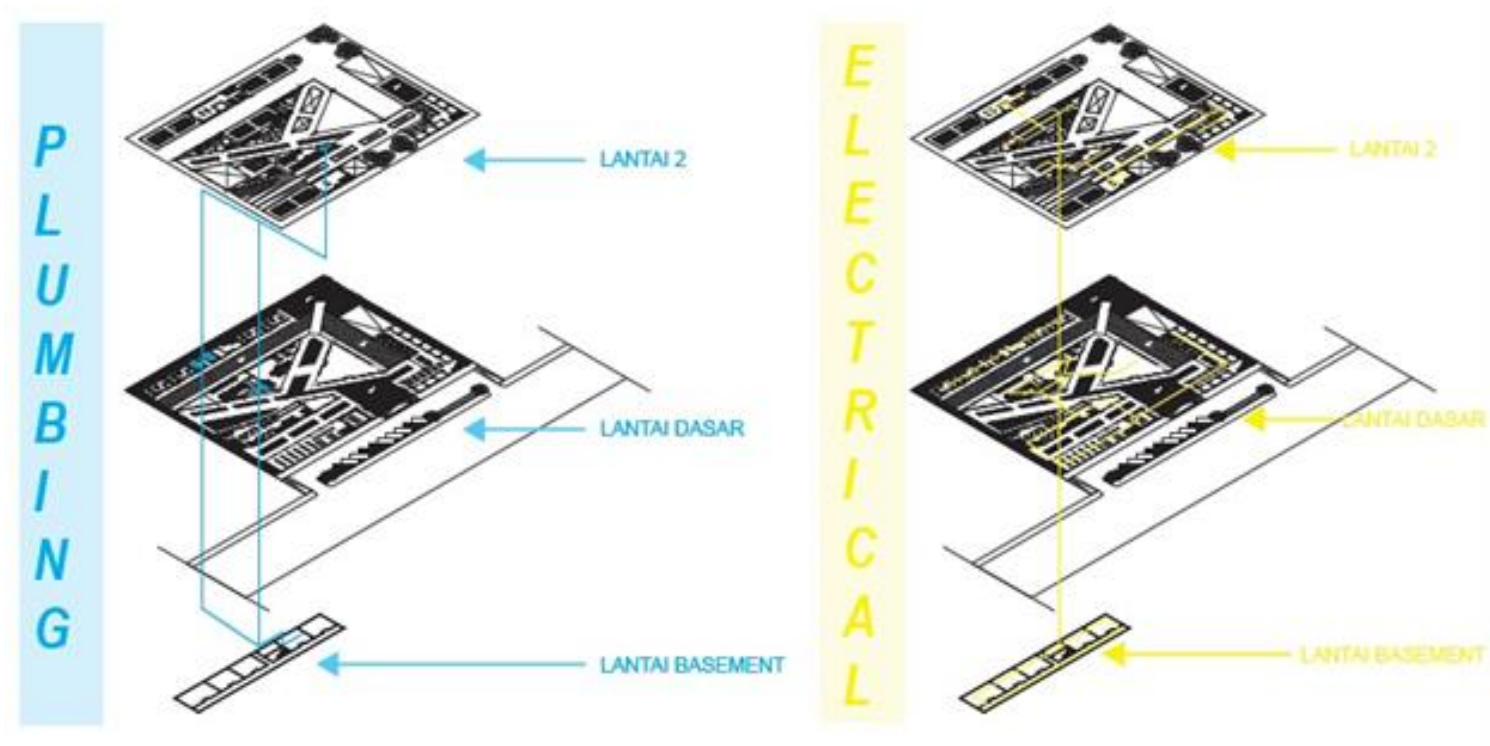

Gambar 9. Gambar Axonometri Utilitas

Sumber : Penulis, 2019

Ruang lingkup pekerjaan elektrikal dalam suatu bangunan adalah menyangkut persediaan sarana distribusi listrik dari panel utama ke panel sub distribusi hingga peralatan. Ruang panel utama berada di lantai basement dan menerus ke lantai teratas dengan adanya shaft, lalu dialirkan ke ruang-ruang lain dari ruang panel setiap lantainya. Ruang panel utama dapat mengontrol semua fungsi elektrikal dalam satu bangunan. Sumber listrik bangunan berasal dari gardu listrik dan tenaga listrik cadangan dapat digunakan generator. Sistem pengudaraan mayoritas menggunakan sistem pengudaraan buatan dengan $A C$ dan sebagian lagi menggunakan pengudaraan alami ( untuk ruang-ruang semi outdoor ).

Untuk sistem plumbing; adalah sistem pemipaan dalam bangunan yang memfasilitasi menyediakan air minum, penyaluran air buangan, penyediaan air panas, penyaluran air hujan, pencegahan kebakaran, dan penghawaan. Bangunan direncanakan memiliki GWT yang berfungsi sebagai penampung air di bawah yang akan dipompa ke reservoir atas dan disalurkan ke setiap lantai melalui shaft yang menerus. STP (Sewage Treatment Plant) berfungsi sebagai pengolahan air kotoran agar bisa digunakan kembali menjadi air siram tanaman, dll.

\section{KESIMPULAN DAN SARAN}

Proyek ini bisa menjadi jembatan penghubung antara kehidupan di rumah dan aktifitas kerja, dalam bidang sosial dan ekonomi. Menjadi wadah untuk kegiatan informal atau nongkrong menghabiskan waktu, menunggu redanya kemacetan lalu lintas sebelum pulang ke rumah dan menjadi wadah bagi warga kota Jakarta untuk berinteraksi dan bersosialisasi tanpa membedakan status sosial terutama untuk kawasan Kebun Jeruk dan sekitarnya khususnya 
untuk wilayah Kedoya Utara. Proyek ini diharapkan dapat berkembang lebih lanjut di daerah atau kawasan lainnya sehingga bermanfaat bagi masyarakat untuk berinteraksi, bersosialisasi dan berekreasi tanpa membedakan status sosial.

\section{REFERENSI}

Antoniades, C. A. (1992). Poetic of Architecture : Theory of Design. Canada: John Wiley \& Sons.Inc

Daerah Khusus Ibukota Jakarta, dari https://map-bms.wikipedia.org/wiki/Daerah-KhususIbukota-Jakarta

Larice, M. and Macdonald, E. (2007). The Urban Design Reader (second edition) Routledge, NY 2008. Two views of outside in British city centres, Urban Design, Issue 108, 24 -27

Oldenburg, R. (1999). The Good Great Place: Cafes, Coffee Shops, Bookstaores, Bars, Hair Salons, and Other Hangouts at the Heart of a Community. USA: Marlowe \& Company Shelton, B. (1999). Learning from the Japanese City, West Meets East in Urban Design. London: E\&FN Spon 